\title{
Understanding right ventricular dysfunction and functional tricuspid regurgitation accompanying mitral valve disease
}

\author{
Lina Maria Vargas Abello, MD, ${ }^{\mathrm{a}}$ Allan L. Klein, MD, ${ }^{\mathrm{b}}$ Thomas H. Marwick, MD, PhD, ${ }^{\mathrm{b}}$ \\ Edward R. Nowicki, MD, MS, ${ }^{\mathrm{a}}$ Jeevanantham Rajeswaran, MSc, ${ }^{\mathrm{c}}$ Sarinya Puwanant, MD, FASE, ${ }^{\mathrm{b}}$ \\ Eugene H. Blackstone, MD, ${ }^{\mathrm{a}, \mathrm{c}}$ and Gösta B. Pettersson, $\mathrm{MD}, \mathrm{PhD}^{\mathrm{a}}$
}

\begin{abstract}
Objectives: The study objective was to correlate the degree of tricuspid regurgitation with clinical indicators of right-sided heart failure and both qualitative and quantitative measures of right-sided heart morphology and function in patients with degenerative mitral valve disease.
\end{abstract}

\begin{abstract}
Methods: From 2001 to 2007, 1833 patients with degenerative mitral valve disease, structurally normal tricuspid valve, and no coronary artery disease underwent surgery. Right-sided heart morphology (right ventricular base-to-apex length, tethering distance and area, and right atrial systolic area) and right ventricular function (tricuspid annular plane systolic excursion, myocardial performance index, and tricuspid valve annular shortening) were measured on preoperative transthoracic echocardiograms for 100 randomly selected patients from each of tricuspid regurgitation grades $0,1+$, and $2+$, and for all 93 patients with tricuspid regurgitation grade $3+/ 4+$. Multivariable regression was used to evaluate the association of left- and right-sided heart morphology and function with tricuspid regurgitation.
\end{abstract}

Results: Increasing tricuspid regurgitation grade was associated with higher right ventricular pressure $(P<.0001)$, increased tethering distance $(P=.008)$, larger right atrial size $(P=.0002)$, and worsening right ventricular function, particularly when $3+4+$ tricuspid regurgitation was present. When tricuspid regurgitation was $3+4+$, both tricuspid annular plane systolic excursion and myocardial performance index were almost certainly abnormal. Changes in right-sided heart morphology and right ventricular dysfunction were synergistic in relation to severity of tricuspid regurgitation.

Conclusions: Functional tricuspid regurgitation accompanying mitral valve disease is associated with proportional changes in right-sided heart morphology; however, severe tricuspid regurgitation is nearly always associated with right ventricular dysfunction, suggesting a synergistic relationship. Right ventricular dysfunction is likely as important as tricuspid regurgitation because it offers an explanation for the negative prognostic impact of tricuspid regurgitation and has implications for the clinical management of patients. (J Thorac Cardiovasc Surg 2013;145:1234-41)

Supplemental material is available online.

Tricuspid regurgitation (TR) accompanying left-sided heart valve disease has long been recognized as a risk factor for early and late mortality after surgery. ${ }^{1,2}$ Although this TR

\footnotetext{
From the Department of Thoracic and Cardiovascular Surgery a and Department of Cardiovascular Medicine, ${ }^{\mathrm{b}}$ Heart and Vascular Institute, and Department of Quantitative Health Sciences, ${ }^{\mathrm{c}}$ Research Institute, Cleveland Clinic, Cleveland, Ohio.

This study was supported in part by the Kenneth Gee and Paula Shaw, PhD, Chair in Heart Research (Dr Blackstone) and the Peter and Elizabeth C. Tower and Family Endowed Chair in Cardiothoracic Research, James and Sharon Kennedy, the Slosburg Family Charitable Trust, and Stephen and Saundra Spencer (Dr Pettersson). No support from industry was received.

Disclosures: Authors have nothing to disclose with regard to commercial support.

Received for publication July 16, 2010; revisions received Dec 7, 2011; accepted for publication Jan 4, 2012; available ahead of print May 24, 2012.

Address for reprints: Gösta B. Pettersson, MD, PhD, Department of Thoracic and Cardiovascular Surgery, Cleveland Clinic, 9500 Euclid Avenue/Mail Stop J4-1, Cleveland, OH 44195 (E-mail: petterg@ ccf.org).

$0022-5223 / \$ 36.00$

Copyright (c) 2013 by The American Association for Thoracic Surgery doi:10.1016/j.jtcvs.2012.01.088
}

is simply considered secondary to right ventricular (RV) dilatation in response to left-sided events and is usually referred to as "functional,",3 its cause remains uncertain. ${ }^{4} \mathrm{We}$ hypothesized that left-sided events resulting in TR also lead to $\mathrm{RV}$ dysfunction. If true, recognizing this has important implications for preoperative surveillance, operative timing, choice of procedure, and postoperative management. Therefore, the objectives of this study were to correlate the degree of TR with clinical indicators of right-sided heart failure and both qualitative and quantitative measures of right-sided heart morphology and function in patients with degenerative mitral valve disease.

\section{PATIENTS AND METHODS Patients}

From January 2001 to January 2007, 2726 patients underwent primary mitral valve repair or replacement for degenerative mitral valve disease at Cleveland Clinic. Of these patients, 1833 had no structural tricuspid valve (TV) pathology and either no clinical suspicion of coronary artery disease or no angiographically significant (stenosis $<50 \%$ ) coronary artery disease; on the basis of clinical preoperative transthoracic echocardiogram assessment, 794 patients had no TR, 645 patients had grade 1+ TR, 301 


$$
\begin{aligned}
\text { Abbreviations and Acronyms } \\
\text { LA }=\text { left atrial } \\
\text { LV } \quad \text { left ventricular } \\
\text { MELD }=\text { Model for End-stage Liver Disease } \\
\text { MPI }=\text { myocardial performance index } \\
\text { RA } \quad \text { right atrial } \\
\text { RV } \quad \text { right ventricular } \\
\text { RVSP }=\text { right ventricular systolic pressure } \\
\text { TAPSE }=\text { tricuspid annular plane systolic } \\
\text { TR } \quad \text { excursion } \\
\text { TV } \quad \text { tricuspid regurgitation }
\end{aligned}
$$

patients had 2+TR, 75 patients had 3+TR, and 18 patients had 4+TR. By using standard American Society of Echocardiography criteria, grading of TR included evaluation of the color TR jet area/right atrial (RA) area, vena contracta, proximal isovelocity surface area, and hepatic vein flow reversal. ${ }^{5-7}$

\section{Study Design}

Our strategy in studying the right side of the heart in relation to degree of TR was a quasi-experimental one, randomly sampling 100 patients from each TR grade $0,1+$, and 2+, but including all 93 patients with TR grades $3+$ and $4+$ (SAS PROC PLAN, SAS Institute Inc, Cary, NC). Thus, 393 patients formed the study cohort, $21 \%$ of the original 1833 patients (Figure E1).

Preoperative and operative data were retrieved from the Cardiovascular Information Registry (Table 1). Hemodynamic state at anesthesia induction was obtained from the Cardiothoracic Anesthesia Registry. Routine echocardiographic assessment of left ventricular (LV), RV, and atrial dimensions and functions were retrieved from the echocardiography database (Table 2). Data from these registries have been approved for use in research by the institutional review board, with patient consent waived.

Left-sided heart morphology and function. Left-sided heart evaluation was by the original routine clinical assessment only. Variables included quantitative measures of LV dimensions and volumes, hypertrophy, and function; left atrial (LA) dimensions; and RV systolic pressure (RVSP) estimated from TV regurgitant jet velocity (Appendix 1). ${ }^{8}$

Right-sided heart morphology and function. Original clinical assessment. Echocardiographic data retrieved from original clinical assessment (Appendix 1) included TR degree, qualitative assessment of RV and RA dilatation, and qualitative assessment of RV dysfunction.

Quantitative right-sided heart morphology. Quantitative assessment of right-sided heart morphology was performed de novo offline on recorded echocardiograms using ProSolv cardiovascular analyzer 3.5 (ProSolv Cardiovascular, Indianapolis, Ind). Measurements averaged over 3 beats were obtained from the apical 4-chamber view:

- RA end-systolic area: planimetric area at end systole (Figure E2, A)

- RV base-to-apex length: distance between midpoint of TV annular plane and RV apex at end diastole (Figure E2, B)

- TV tethering distance: distance between coaptation point of TV cusps and TV annular plane (Figure E2, $C$ )

- TV tethering area: planimetric area between atrial surface of TV cusps and tricuspid annular plane at end diastole (Figure E2, D)
Quantitative right ventricular function. Quantitative assessment of RV function was performed de novo offline using the apical 4-chamber and parasternal RV inflow and outflow tract views.

- Tricuspid annular plane systolic excursion (TAPSE) (Figure E3): displacement of lateral portion of TV annulus from diastole to systole, averaged over 3 beats $(\mathrm{cm}) .{ }^{9}, 10$ Normal TAPSE is $1.5 \mathrm{~cm}$ or more and decreases with diminishing systolic function.

- Myocardial performance index (MPI) (Figure E4): ratio of total isovolumetric contraction plus relaxation times and pulmonary ejection time $\mathrm{e}^{8,11-14}$ averaged over 3 beats. Normal MPI is 0.4 or less and increases with diminishing global systolic and diastolic function.

- TV annular shortening (Figure E5): difference between diastolic and systolic TV annulus diameters. TV annulus diameter is the distance between points of attachment of anterior and septal TV cusps on the mural and septal endocardia, respectively. ${ }^{15}$

- TV annular fractional shortening: ratio of TV annulus shortening and diastolic TV annulus diameter. ${ }^{15,16}$

Clinical indicators of right-sided heart failure. Variables constituting the Model for End-stage Liver Disease (MELD) score-creatinine, bilirubin, and international normalized ratio-and the MELD score itself were considered indicators of possible right-sided heart failure. ${ }^{17}$

\section{Data Analysis}

Multivariable analyses of tricuspid regurgitation grade. Multivariable analysis of TR grade, using variables listed in Appendix 1, was performed using cumulative logistic regression. Five sequential analyses of cardiac morphology and function were performed:

1. Analysis of left-sided heart variables: degree of mitral regurgitation, LV inner diameter and volume diastole and systole, posterior wall and septal thickness, relative wall thickness, calculated LV mass, LV fractional shortening, ejection fraction, RVSP, and LA diameter, volume, and systolic area.

2. Analysis of qualitative right-sided heart variables: qualitative RV and RA dilatation and RV dysfunction. Because of low frequencies in the mild-moderate-severe categories, we collapsed these, treating them as binary variables.

3. Analysis of quantitative right-sided heart morphology variables: RA systolic area in systole, RV base-to-apex length, and TV tethering distance and area.

4. Analysis of quantitative RV function variables: TAPSE, MPI, and TV annular and fractional shortening.

5. Analysis of all left- and right-sided heart variables: All these variables were included in a final analysis presented in this article.

Management of missing data and variable selection strategy. Fivefold multiple imputation using a Markov Chain MonteCarlo technique was performed to impute sporadic missing values under the assumption of missing at random. ${ }^{18}$ Multivariable analyses were then performed using the first imputed sample. Variable selection, with a $P$ value retention criterion of .05 , used bagging for 1000 bootstrap samples. ${ }^{19,20}$ Frequency of occurrence of individual variables and clusters of correlated variables was compiled, and those appearing in at least $50 \%$ of analyses were retained in final models. After variable selection, 4 additional imputed complete data sets were formed to estimate regression coefficients and their variance-covariance matrix. ${ }^{18}$

\section{Data Presentation}

Continuous variables are summarized by mean \pm standard deviation, and categoric variables are summarized by frequencies and percentages. All analyses were performed using SAS statistical software (SAS V9.1). Uncertainty is expressed by confidence limits equivalent to \pm 1 standard error $(68 \%)$. 
TABLE 1. Preoperative patient characteristics according to tricuspid regurgitation grade

\begin{tabular}{|c|c|c|c|c|c|c|c|c|c|}
\hline \multirow[b]{3}{*}{ Variable } & \multicolumn{8}{|c|}{ TV regurgitation grade } & \multirow[b]{3}{*}{$\boldsymbol{P} \dagger$} \\
\hline & \multicolumn{2}{|c|}{$\mathbf{0}(\mathbf{n}=100)$} & \multicolumn{2}{|c|}{$1+(n=100)$} & \multicolumn{2}{|c|}{$2+(n=100)$} & \multicolumn{2}{|c|}{$3+/ 4+(n=93)$} & \\
\hline & $\mathbf{n}^{*}$ & $\begin{array}{l}\text { No. }(\%) \text { or } \\
\text { Mean } \pm \text { SD }\end{array}$ & $\mathbf{n}^{*}$ & $\begin{array}{l}\text { No. }(\%) \text { or } \\
\text { Mean } \pm \text { SD }\end{array}$ & $\mathbf{n}^{*}$ & $\begin{array}{l}\text { No. }(\%) \text { or } \\
\text { Mean } \pm \text { SD }\end{array}$ & $\mathbf{n}^{*}$ & $\begin{array}{l}\text { No. }(\%) \text { or } \\
\text { Mean } \pm \text { SD }\end{array}$ & \\
\hline \multicolumn{10}{|l|}{ Demographics } \\
\hline Age (y) & 100 & $53 \pm 10$ & 100 & $57 \pm 12$ & 100 & $65 \pm 12$ & 93 & $68 \pm 11$ & $<.0001$ \\
\hline Female & 100 & $31(31)$ & 100 & $37(37)$ & 100 & $34(34)$ & 93 & $52(56)$ & .002 \\
\hline Body surface area $\left(\mathrm{m}^{2}\right)$ & 100 & $2 \pm 0.23$ & 100 & $2 \pm 0.25$ & 100 & $2 \pm 0.23$ & 93 & $1.9 \pm 0.24$ & .001 \\
\hline \multicolumn{10}{|l|}{ Cardiac morbidity } \\
\hline NYHA functional class & 100 & & 100 & & 100 & & 93 & & .04 \\
\hline I & & $33(33)$ & & $28(28)$ & & $36(36)$ & & $18(19)$ & \\
\hline II & & $53(53)$ & & $63(63)$ & & $52(52)$ & & $54(58)$ & \\
\hline III & & $14(14)$ & & $8(8)$ & & $11(11)$ & & $20(22)$ & \\
\hline IV & & $0(0)$ & & $1(1)$ & & $1(1)$ & & $1(1.1)$ & \\
\hline \multicolumn{10}{|l|}{ Noncardiac comorbidity } \\
\hline Cholesterol (mg/dL) & 93 & $200 \pm 38$ & 87 & $200 \pm 43$ & 92 & $190 \pm 29$ & 85 & $180 \pm 35$ & $<.0001$ \\
\hline Bilirubin (mg/dL) & 100 & $0.72 \pm 0.59$ & 97 & $0.74 \pm 0.39$ & 99 & $0.8 \pm 0.41$ & 89 & $0.87 \pm 0.52$ & .03 \\
\hline Blood urea nitrogen $(\mathrm{mg} / \mathrm{dL})$ & 99 & $17 \pm 4.8$ & 100 & $18 \pm 5.3$ & 100 & $19 \pm 6$ & 93 & $22 \pm 8.8$ & $<.0001$ \\
\hline Creatinine (mg/dL) & 100 & $0.93 \pm 0.19$ & 99 & $0.96 \pm 0.23$ & 99 & $1 \pm 0.24$ & 92 & $1.1 \pm 0.7$ & .02 \\
\hline Hematocrit (\%) & 98 & $42 \pm 3.5$ & 99 & $41 \pm 5.4$ & 99 & $41 \pm 4$ & 90 & $40 \pm 4.7$ & .0001 \\
\hline MELD score & 100 & $7.2 \pm 1.4$ & 100 & $7.4 \pm 1.6$ & 100 & $8 \pm 2.4$ & 93 & $8.6 \pm 2.4$ & $<.0001$ \\
\hline
\end{tabular}

$T V$, Tricuspid valve; SD, standard deviation; NYHA, New York Heart Association; MELD, Model for End-stage Liver Disease. *Patients with data available. $\dagger$ For categoric variables, Mantel-Haenszel test of linear trend with increasing TV regurgitation grade; for continuous variables, equivalent test of Pearson correlation coefficient.

\section{RESULTS}

\section{Tricuspid Regurgitation and Patient Factors}

Increasing TR was associated with older age, female gender, smaller body surface area, impaired hepatic function (higher bilirubin and higher MELD score), lower serum cholesterol, higher blood urea nitrogen, and lower hematocrit. Severity of TR was also weakly associated with higher New York Heart Association functional class (Table 1).

\section{Tricuspid Regurgitation and Left- and Right-Sided Heart Findings}

Degree of TR was not correlated with degree of mitral regurgitation (by selection, all patients had at least moderate regurgitation) but was strongly positively correlated with higher RVSP (Figure E6) and LA diameter. TR was also weakly associated with lower LV ejection fraction and smaller LV end-diastolic volume, but not with LV hypertrophy (Table 2).

Degree of TR was closely correlated with degree of pulmonary valve regurgitation and both qualitative and quantitative measures of RV function (Table 2).

Routine qualitative echocardiographic assessment of right-sided heart morphology (Figure E7, $A$ and $B$ ) and function (Figure E7, C), however, showed positive, but weak, correlations with degree of TR. In contrast, quantitative measurements of RA area (Figure E8, $A$ ), TV tethering distance (Figure E8, B) and area, and RV base-to-apex length were all positively correlated with degree of TR.

Abnormal TAPSE and MPI separated patients with severe TR $3+4+$ from those with lower grades of TR. TAPSE was substantially lower (worse function) for patients with TR $3+4+$ and, in this lower range, less variable than at lower grades of TR (Figure 1, $A$ and $B$ ). MPI was considerably higher (worse function) for TR $3 / 4+$, but more variable than at lower grades (Figure 1, $C$ and $D$ ). There were low to moderate correlations $(|\mathrm{r}|>0.1)$ between quantitative measures of right-sided heart morphology and TAPSE and MPI (Figure E9, $A$ and $B) .^{21}$

Higher values of TAPSE were associated with lower values of MPI (inverse relationship, $r=-0.74, P<.0001$ ) in a nonlinear fashion (Figure E10). At low TAPSE levels, MPI values stretched toward higher levels. The interaction between TAPSE and MPI in patients with severe TR $3+14+$ is illustrated in a 3-dimensional perspective plot (Figure E11).

Patient variables associated with lower TAPSE were older age, higher New York Heart Association class, larger LA volume, atrial fibrillation, lower creatinine clearance, lower cholesterol (Table 3), and with higher MPI, older age, increased heart rate, larger LA volume, lower creatinine clearance, lower cholesterol, higher MELD score, complete heart block, smaller LV end-diastolic volume, and lower hematocrit (Table 3).

\section{Tricuspid Regurgitation and Multivariable Association With Cardiac Morphology and Right Ventricular Function}

In multivariable analysis, cardiac morphologic variables associated with higher grade of TR included smaller LV and end-systolic volume, large RA systolic area, and larger 
TABLE 2. Left- and right-sided heart echocardiographic findings according to tricuspid regurgitation grade

TV regurgitation grade

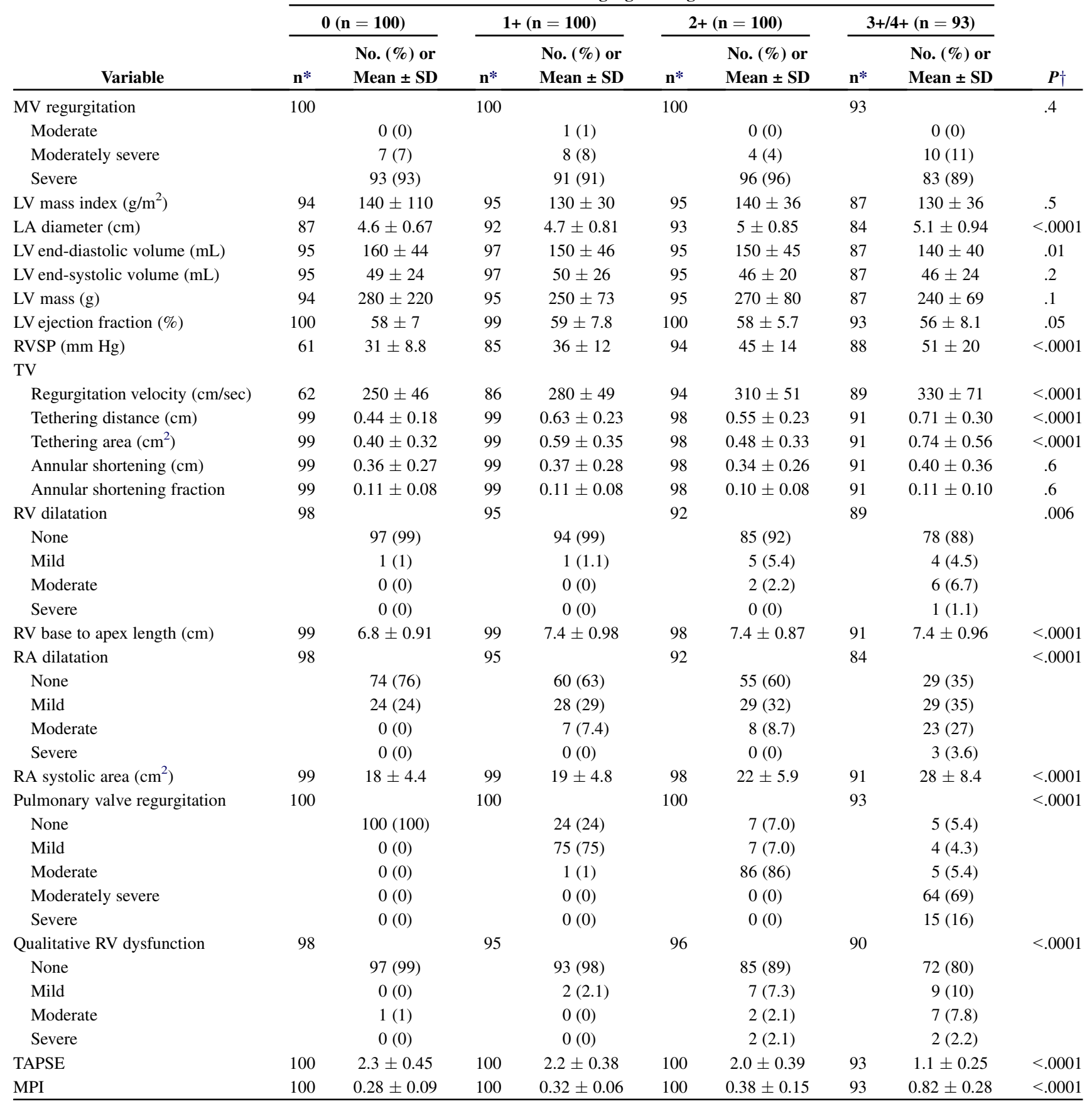

$T V$, Tricuspid valve; $S D$, standard deviation; $M V$, mitral valve; $L V$, left ventricular; $L A$, left atrial; $R V S P$, right ventricular systolic pressure; $R V$, right ventricular; $R A$, right atrial; TAPSE, tricuspid annular plane systolic excursion; MPI, myocardial performance index. *Patients with data available. †For categoric variables, Mantel-Haenszel test of linear trend with increasing TV regurgitation grade; for continuous variables, equivalent test of Pearson correlation coefficient.

tethering distance (Figure E12, $A$ and $B$; Table 4). RVSP was proportionately higher in higher grades of TR. Lower (worse) TAPSE and higher (worse) MPI were associated with higher TR grade.

\section{DISCUSSION}

\section{Study Design}

Previous attempts to understand functional TR have focused on patients already exhibiting marked RV 

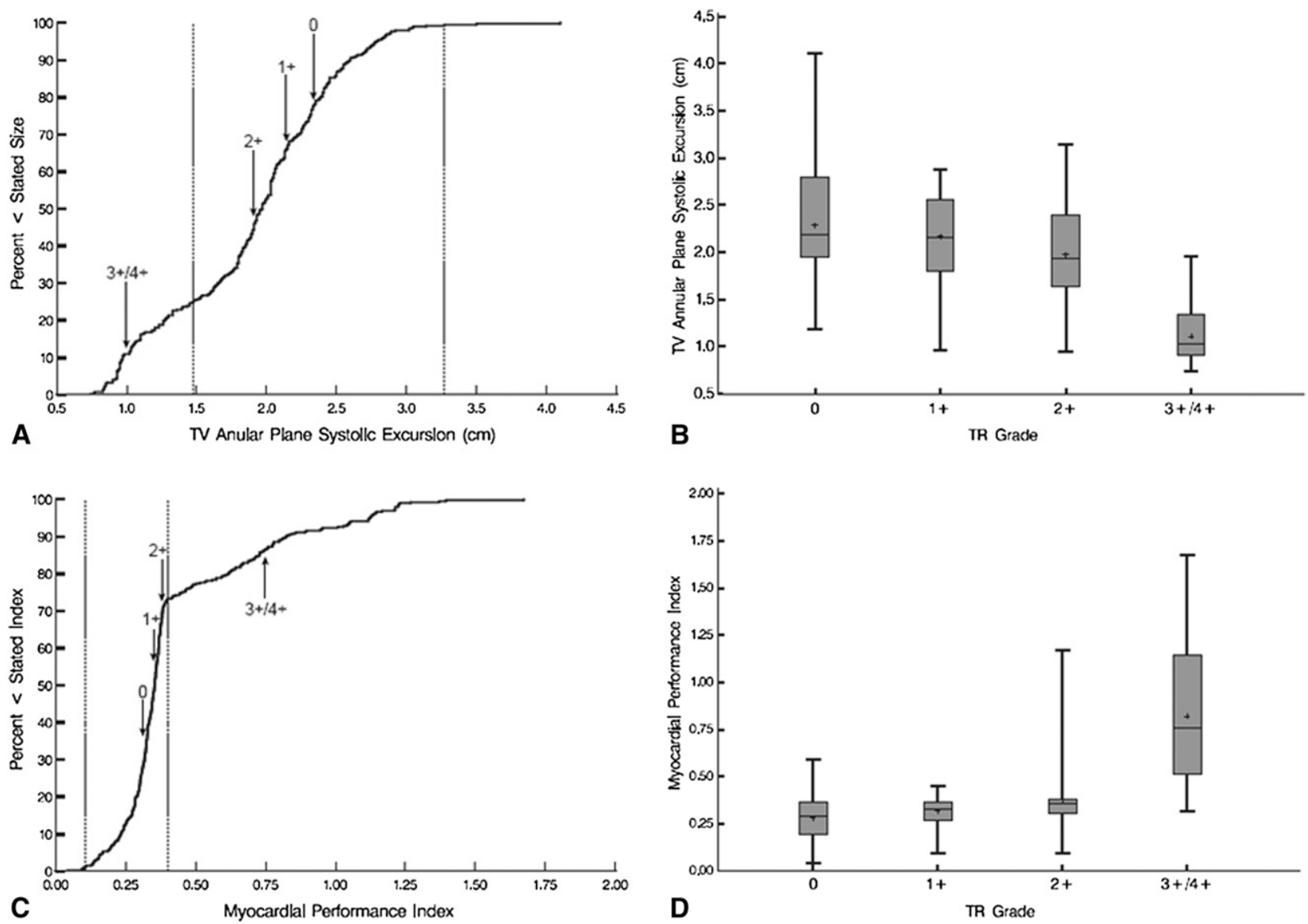

FIGURE 1. TR and RV function. A, Cumulative distribution of TAPSE. Vertical dashed lines represent $95 \%$ confidence limits for patients without TR. Arrows point to median value for each TR grade. B, Box and whiskers plot of TAPSE and TR grade. Whiskers represent extreme values, boxes represent the 15 th and 85 th percentile of values, + sign represents the mean, and horizontal bar represents the median values. C, Cumulative distribution of MPI. Format is as in A. D, Box and whiskers plot of MPI and TR grade. Format is as in B. $T R$, Tricuspid regurgitation; $R V$, right ventricular.

enlargement ${ }^{22}$ or important TR. ${ }^{4}$ This approach presumes a mechanism for functional TR: RV dilatation. This study, in contrast, has taken a quasi-experimental approach, examining the entire spectrum of right-sided heart morphology and function in patients with no, mild, moderate, and severe TR. We were careful not to include patients with structural TV disease, intrinsic RV disease, or evidence of coronary artery disease. Our patients also had a homogeneous leftsided valve lesion: degenerative mitral valve disease with severe mitral regurgitation requiring operation.

\section{Tricuspid Regurgitation and Right Ventricular Morphology and Function}

Overall, with these exclusion criteria, $5 \%$ of patients undergoing surgery for degenerative mitral valve disease with mitral regurgitation had severe functional TR. The surgical mindset has been that functional TR is caused by changes in RV morphology during systole-size and shape of the annulus, distance from annulus to papillary muscles, and relative displacement of individual papillary muscles. Leaflet tethering is a consequence of TV and RV dilatation. ${ }^{23-25}$ This concept of mechanism underlies the choice of repair procedure: annulus size reduction (annuloplasty, ring size), annulus reshaping (rigid vs flexible ring), valve replacement when papillary muscle splaying prevents annulus reduction, and reshaping from making the TV competent. Yet, no single repair technique has proven consistently effective in sustained elimination of functional TR, nor do surgeons believe that TV replacement leads to better prognosis. This study emphasizes associated RV dysfunction, which might not be cured with any TV procedure.

All measures of altered right-sided heart morphology and RV dysfunction, qualitative and quantitative, correlated with the degree of TR. Even so, we were impressed by the poor correlation of routine quantitative measures of the right heart- RA dilatation and RV dilatation and dysfunction-with degree of TR. However, comparing our study with other studies of functional $\mathrm{TR}^{4,22}$ revealed several differences. The study populations are defined and selected differently. Our population was defined by 
TABLE 3. Patient factors associated with worse right ventricular function

\begin{tabular}{|c|c|c|c|}
\hline Factor & Coefficient \pm SD & $\boldsymbol{P}$ & $\begin{array}{c}\text { Reliability } \\
(\%)^{*} \\
\end{array}$ \\
\hline \multicolumn{4}{|l|}{ Lower TAPSE } \\
\hline Older age $\dagger$ & $-0.12 \pm 0.0403$ & .002 & 77 \\
\hline Higher NYHA $\ddagger$ functional class & $0.28 \pm 0.104$ & .007 & 45 \\
\hline $\begin{array}{l}\text { Larger LA volume index } \\
\qquad\left(\mathrm{mL} / \mathrm{m}^{2}\right) \S\end{array}$ & $3.6 \pm 1.5$ & .02 & 73 \\
\hline Atrial fibrillation & $-0.27 \pm 0.075$ & .0003 & 87 \\
\hline $\begin{array}{l}\text { Lower creatinine clearance } \\
\qquad(\mathrm{mL} / \mathrm{min}) \|\end{array}$ & $0.24 \pm 0.093$ & .009 & 68 \\
\hline Lower cholesterol (mg/dL) $\uparrow$ & $0.036 \pm 0.018$ & .04 & 47 \\
\hline \multicolumn{4}{|l|}{ Higher MPI } \\
\hline Older age\# & $0.18 \pm 0.041$ & $<.0001$ & 66 \\
\hline $\begin{array}{l}\text { Increased heart rate } \\
\text { (beats/min)** }\end{array}$ & $0.13 \pm 0.055$ & .02 & 70 \\
\hline Larger LA systolic area $\left(\mathrm{cm}^{2}\right) \dagger \dagger$ & $-7.7 \pm 3.0$ & .01 & 94 \\
\hline $\begin{array}{l}\text { Lower creatinine clearance } \\
\qquad(\mathrm{mL} / \mathrm{min}) \ddagger \ddagger\end{array}$ & $0.15 \pm 0.044$ & .0008 & 80 \\
\hline Lower cholesterol (mg/dL) $\S \S$ & $0.40 \pm 0.18$ & .02 & 55 \\
\hline Higher MELD score \|\| & $-0.39 \pm 0.092$ & $<.0001$ & 73 \\
\hline Complete heart block & $0.38 \pm 0.16$ & .02 & 61 \\
\hline $\begin{array}{l}\text { Smaller LV diastolic volume } \\
(\mathrm{mL}) \boldsymbol{\top}\end{array}$ & $2.7 \pm 1.3$ & .04 & 63 \\
\hline Lower hematocrit (\%)\#\# & $2.7 \pm 1.3$ & .04 & 63 \\
\hline \multicolumn{4}{|c|}{ 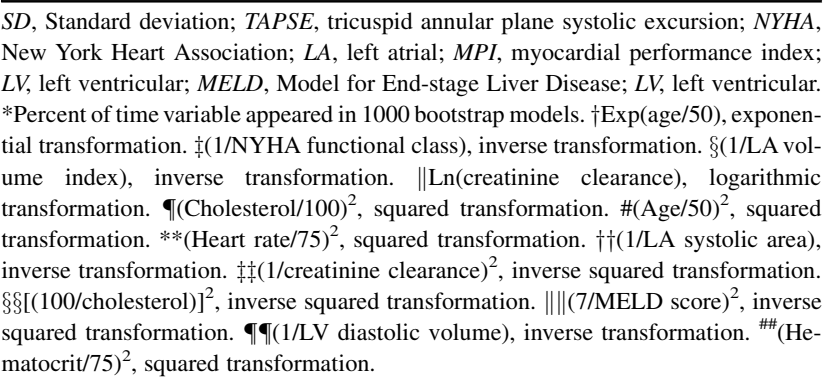 } \\
\hline
\end{tabular}

a single diagnosis: degenerative mitral valve disease with severe regurgitation. Fukuda and colleagues ${ }^{4}$ studied patients with severe TR $(>2+)$ accompanying any left-sided heart disease; Kim and colleagues ${ }^{22}$ studied patients with enlarged RVs with any diagnosis and any degree of TR. In these and the present study, leaflet tethering and dilatation were correlated with degree of TR, yet the weakness of the correlation suggests that the mechanism of TR is multifactorial and variable from case to case. Our study emphasizes the stronger correlation between severe TR and RV dysfunction assessed by the less frequently measured quantities, TAPSE and MPI. Kim and colleagues ${ }^{22}$ also found a correlation between TR and RV dysfunction using RV fractional area change as a measure of RV function.

TAPSE and MPI are considered standard assessment tools for RV function. ${ }^{26}$ TAPSE is easily measured and reflects longitudinal excursion occurring during systole and has been validated as a measure of systolic RV function. $^{7,9,27}$ It is more highly correlated with magnetic
TABLE 4. Left- and right-sided heart morphology and right and left ventricular function associated with higher grade of preoperative tricuspid valve regurgitation

\begin{tabular}{lccc}
\hline \multicolumn{1}{c}{ Factor } & Coefficient \pm SD & $\boldsymbol{P}$ & $\begin{array}{c}\text { Reliability } \\
(\%)\end{array}$ \\
\hline Morphology & & & \\
$\quad$ Smaller LV end-systolic & $-0.47 \pm 0.22$ & .03 & 67 \\
$\quad$ volume $\left(\mathrm{mL} / \mathrm{m}^{2}\right) \dagger$ & & & \\
Larger RA area in systole $\ddagger$ & $0.64 \pm 0.17$ & .0002 & 85 \\
Longer TV tethering distance & $0.74 \pm 0.28$ & .008 & 82 \\
$\quad(\mathrm{~cm}) \S$ & & & \\
Function & & & \\
Higher RVSP $(\mathrm{mm}$ Hg) & $0.042 \pm 0.0088$ & $<.0001$ & 99 \\
$\quad$ Worse TAPSE $\|$ & $-7.1 \pm 1.3$ & $<.0001$ & 96 \\
$\quad$ Worse MPI & $5.1 \pm 0.92$ & $<.0001$ & 100 \\
$\quad$ Interaction: TAPSE $\cdot$ MPI\# & $-3.9 \pm 1.2$ & .0009 & \\
\hline
\end{tabular}

$S D$, Standard deviation; $L V$, Left ventricular; $R A$, right atrial; $T V$, tricuspid valve $R V S P$, right ventricular systolic pressure; TAPSE, tricuspid annular plane systolic excursion; $M P I$, myocardial performance index. *Percent of time variable appeared in 1000 bootstrap models. $\dagger$ (LV end-systolic volume/75) ${ }^{2}$, squared transformation. $\ddagger$ (RA area in systole $/ 20)^{2}$, squared transformation. $\S \log (\mathrm{TV}$ tethering distance), logarithmic transformation. | Log(TAPSE), logarithmic transformation. $\uparrow \log (\mathrm{MPI}), \operatorname{loga}$ rithmic transformation. \#Interaction: $\log (\mathrm{TAPSE}) \cdot \log (\mathrm{MPI})$

resonance imaging-derived volumes ${ }^{28}$ and radionuclide ejection fraction ${ }^{29}$ than other previously described more complex measures, such as change in RV area during systole. ${ }^{9,30,31}$ MPI comprises energy-dependent periods of contraction, ejection, and relaxation. ${ }^{12} \mathrm{RV}$ isovolumetric relaxation time is prolonged with diastolic dysfunction, and isovolumetric contraction and ejection times increase with systolic dysfunction. MPI is correlated with invasive hemodynamic measures of RV function ${ }^{32,33}$ and ejection fraction by ventriculography.

TR is more than a simple consequence of RV dilatation. Unlike the linear relation of RVSP with increasing TR grade, there was a stepwise worsening of RV function, as reflected by TAPSE and MPI, from TR grade $2+$ or less to severe $3+4+$. A threshold seems to exist above which severe TR did not occur without RV dysfunction. TAPSE and MPI were complementary: As TAPSE became abnormal, there was not much variation among the values; in contrast, MPI exhibited wide variation among abnormal values.

LV dysfunction has also been proposed as a mechanism for producing functional TR through interventricular septal interaction causing RV dysfunction. ${ }^{34}$ In this study, we observed a reversed interaction in that the severe TR was associated with smaller LV end-diastolic volume, suggesting interventricular dependence with septal shift toward the left from high right-sided filling pressure and RV volume overload.

\section{Clinical Implications}

The strong correlation between TR and RV dysfunction has clinical implications beyond surgical technique and focuses attention on the indication for and timing of surgery, 
postoperative management, and prognosis. It suggests that earlier surgery should be performed before RV function deteriorates. Surgeons must also develop greater awareness of the implications of RV dysfunction in postoperative management. TV repair might be of little help if the RV has limited capacity to take advantage of a competent valve. Such a scenario offers an explanation for TR as a predictor of early and late mortality in patients undergoing operation for left-sided heart disease. ${ }^{1,2}$

\section{Limitations}

Severity of TR was evaluated qualitatively and not quantified; however, all clinical readers were using standard American Society of Echocardiography grading criteria. We did not assess intra- or interobserver variability in estimating severity of TR, but accepted the readings used for clinical decision-making. Although it is asserted that TAPSE and MPI are afterload and preload independent, we cannot discount the possibility that with severe TR, these measures may not solely reflect intrinsic RV function, making the correlations artificially stronger. Studies of RV strain and 3-dimensional echocardiography may enhance understanding the complex relationship between RV function and TR. Response to surgery is presented in a companion article.

\section{CONCLUSIONS}

Functional TR is associated with proportional changes in right-sided heart morphology; however, severe TR is nearly always associated with RV dysfunction, suggesting a synergistic relationship. RV dysfunction is likely to be as important as TR because it offers a credible explanation for the negative prognostic impact of TR and has implications for the clinical management of patients. Better evaluation of $\mathrm{RV}$ function requires adding quantitative echocardiographic measures, such as easily measured TAPSE and MPI, to preoperative assessment of these patients.

\section{References}

1. Braunwald NS, Ross J Jr, Morrow AG. Conservative management of tricuspid regurgitation in patients undergoing mitral valve replacement. Circulation. 1967;35(4 Suppl):I63-9.

2. Nath J, Foster E, Heidenreich PA. Impact of tricuspid regurgitation on long-term survival. J Am Coll Cardiol. 2004;43:405-9.

3. Cohen SR, Sell JE, McIntosh CL, Clark RE. Tricuspid regurgitation in patients with acquired, chronic, pure mitral regurgitation. I. Prevalence, diagnosis, and comparison of preoperative clinical and hemodynamic features in patients with and without tricuspid regurgitation. J Thorac Cardiovasc Surg. 1987;94:481-7.

4. Fukuda S, Gillinov AM, Song JM, Daimon M, Kongsaerepong V, Thomas JD, et al. Echocardiographic insights into atrial and ventricular mechanisms of functional tricuspid regurgitation. Am Heart J. 2006;152:1208-14.

5. Nagueh SF. Assessment of valvular regurgitation with Doppler echocardiography. Cardiol Clin. 1998;16:405-19. vii.

6. Zoghbi WA, Enriquez-Sarano M, Foster E, Grayburn PA, Kraft CD, Levine RA, et al. Recommendations for evaluation of the severity of native valvular regurgitation with two-dimensional and Doppler echocardiography. J Am Soc Echocardiogr. 2003;16:777-802.
7. Cooper JW, Nanda NC, Philpot EF, Fan P. Evaluation of valvular regurgitation by color Doppler. J Am Soc Echocardiogr. 1989;2:56-66.

8. Lang RM, Bierig M, Devereux RB, Flachskampf FA, Foster E, Pellikka PA, et al. Recommendations for chamber quantification: a report from the American Society of Echocardiography's Guidelines and Standards Committee and the Chamber Quantification Writing Group, developed in conjunction with the European Association of Echocardiography, a branch of the European Society of Cardiology. J Am Soc Echocardiogr. 2005;18: 1440-63.

9. Kaul S, Tei C, Hopkins JM, Shah PM. Assessment of right ventricular function using two-dimensional echocardiography. Am Heart J. 1984;107:526-31.

10. Ghio S, Recusani F, Klersy C, Sebastiani R, Laudisa ML, Campana C, et al. Prognostic usefulness of the tricuspid annular plane systolic excursion in patients with congestive heart failure secondary to idiopathic or ischemic dilated cardiomyopathy. Am J Cardiol. 2000;85:837-42.

11. Tei C. New non-invasive index for combined systolic and diastolic ventricular function. J Cardiol. 1995;26:135-6.

12. Burgess MI, Bright-Thomas RJ, Ray SG. Echocardiographic evaluation of right ventricular function. Eur J Echocardiogr. 2002;3:252-62.

13. Tei C, Ling LH, Hodge DO, Bailey KR, Oh JK, Rodeheffer RJ, et al. New index of combined systolic and diastolic myocardial performance: a simple and reproducible measure of cardiac function-a study in normals and dilated cardiomyopathy. J Cardiol. 1995;26:357-66.

14. Lakoumentas JA, Panou FK, Kotseroglou VK, Aggeli KI, Harbis PK. The Tei index of myocardial performance: applications in cardiology. Hellenic J Cardiol. 2005;46:52-8.

15. Fukuda S, Song JM, Gillinov AM, McCarthy PM, Daimon M, Kongsaerepong V, et al. Tricuspid valve tethering predicts residual tricuspid regurgitation after tricuspid annuloplasty. Circulation. 2005;111:975-9.

16. Eidem BW, O'Leary PW, Tei C, Seward JB. Usefulness of the myocardial performance index for assessing right ventricular function in congenital heart disease. Am J Cardiol. 2000;86:654-8.

17. Kamath PS, Kim WR. The model for end-stage liver disease (MELD). Hepatology. 2007;45:797-805.

18. Rubin DB. Multiple Imputation for Nonresponse in Surveys. New York: Wiley; 1997.

19. Breiman L. Bagging predictors. Machine Learning. 1996;24:123-40.

20. Blackstone EH. Breaking down barriers: helpful breakthrough statistical methods you need to understand better. J Thorac Cardiovasc Surg. 2001;122: 430-9.

21. Cleveland WS, Devlin SJ. Locally weighted regression: an approach to regression analysis by local fitting. J Am Stat Assoc. 1988;83:596-610.

22. Kim HK, Kim YJ, Park JS, Kim KH, Kim KB, Ahn H, et al. Determinants of the severity of functional tricuspid regurgitation. Am J Cardiol. 2006;98: 236-42.

23. Tei C, Pilgrim JP, Shah PM, Ormiston JA, Wong M. The tricuspid valve annulus: study of size and motion in normal subjects and in patients with tricuspid regurgitation. Circulation. 1982;66:665-71.

24. Ubago JL, Figueroa A, Ochoteco A, Colman T, Duran RM, Duran CG. Analysis of the amount of tricuspid valve annular dilatation required to produce functional tricuspid regurgitation. Am J Cardiol. 1983;52:155-8.

25. Sagie A, Schwammenthal E, Padial LR, Vazquez de Prada JA, Weyman AE, Levine RA. Determinants of functional tricuspid regurgitation in incomplete tricuspid valve closure: Doppler color flow study of 109 patients. JAm Coll Cardiol. 1994;24:446-53.

26. Rudski LG, Lai WW, Afilalo J, Hua L, Handschumacher MD, Chandrasekaran K, et al. Guidelines for the echocardiographic assessment of the right heart in adults: a report from the American Society of Echocardiography endorsed by the European Association of Echocardiography, a registered branch of the European Society of Cardiology, and the Canadian Society of Echocardiography. J Am Soc Echocardiogr. 2010;23:685-713.

27. Miller D, Farah MG, Liner A, Fox K, Schluchter M, Hoit BD. The relation between quantitative right ventricular ejection fraction and indices of tricuspid annular motion and myocardial performance. $J$ Am Soc Echocardiogr. 2004;17: 443-7.

28. Endo Y, Maddukuri PV, Vieira ML, Pandian NG, Patel AR. Quantification of right ventricular volumes and function by real time three-dimensional echocardiographic longitudinal axial plane method: validation in the clinical setting. Echocardiography. 2006;23:853-9.

29. Ueti OM, Camargo EE, Ueti Ade A, de Lima-Filho EC, Nogueira EA. Assessment of right ventricular function with Doppler echocardiographic indices 
derived from tricuspid annular motion: comparison with radionuclide angiography. Heart. 2002;88:244-8.

30. Mishra M, Swaminathan M, Malhotra R, Mishra A, Trehan N. Evaluation of right ventricular function during CABG: transesophageal echocardiographic assessment of hepatic venous flow versus conventional right ventricular performance indices. Echocardiography. 1998;15:51-8.

31. Savage RM, Aronson S, Thomas JD, Shanewise JS, Shernan SK, eds. Comprehensive Textbook of Intraoperative Transesophageal Echocardiography. Philadelphia: Lippincott Williams \& Wilkins; 2004.
32. Tei C, Dujardin KS, Hodge DO, Bailey KR, McGoon MD, Tajik AJ, et al. Doppler echocardiographic index for assessment of global right ventricular function. $J$ Am Soc Echocardiogr. 1996;9:838-47.

33. Teshima K, Asano K, Iwanaga K, Koie H, Uechi M, Kato Y, et al. Evaluation of right ventricular Tei index (index of myocardial performance) in healthy dogs and dogs with tricuspid regurgitation. J Vet Med Sci. 2006;68:1307-13.

34. Santamore WP, Dell'Italia LJ. Ventricular interdependence: significant left ventricular contributions to right ventricular systolic function. Prog Cardiovasc Dis. 1998;40:289-308.

\section{APPENDIX TABLE 1. Variables used in statistical analyses}

\section{Patient}

Demographic

Symptoms

Valve pathology

Coronary anatomy

Cardiac comorbidity

Heart hemodynamics

Noncardiac comorbidity

Experience

Left heart

Ventricle

Morphology

Function

Atrium

Morphology

Right heart

Ventricle

Morphology

Function

Atrium

Morphology
Age (y), gender, weight $(\mathrm{kg})$, height $(\mathrm{cm})$, body surface area $\left(\mathrm{m}^{2}\right)$, BMI $\left(\mathrm{kg} / \mathrm{m}^{2}\right)$

NYHA functional class (I-IV)

Mitral valve regurgitation, aortic valve regurgitation

Left main trunk disease ( $\%$ stenosis), left anterior descending coronary artery system disease (maximum $\%$ stenosis), right coronary artery system disease (maximum \% stenosis), left circumflex coronary artery system disease (maximum $\%$ stenosis)

Atrial fibrillation, hypertension, history of cardiac disease, complete heart block/pacer, ventricular arrhythmia

Mean arterial pressure $(\mathrm{mm} \mathrm{Hg})$, central venous pressure $\left(\mathrm{cmH}_{2} \mathrm{O}\right)$, heart rate (beats/min)

Treated diabetes, insulin-treated diabetes, peripheral arterial disease, history of smoking, carotid disease, popliteal disease, creatinine $(\mathrm{mg} / \mathrm{dL})$, blood urea nitrogen $(\mathrm{mg} / \mathrm{dL})$, bilirubin $(\mathrm{mg} / \mathrm{dL})$, creatinine clearance $(\mathrm{mL} / \mathrm{min})$, hematocrit $(\%)$, glomerular filtration rate $(\mathrm{mL} / \mathrm{min})$, history of renal disease, previous stroke, MELD score

Date of operation (years since January 1, 2001)

Inner diameter in diastole $(\mathrm{cm})$, inner diameter in systole $(\mathrm{cm})$, diastolic volume $(\mathrm{mL})$, systolic volume $(\mathrm{mL})$, diastolic volume index $\left(\mathrm{mL} / \mathrm{m}^{2}\right)$, systolic volume index $\left(\mathrm{mL} / \mathrm{m}^{2}\right)$, dilated left ventricle, mass $(\mathrm{g})$, mass index $\left(\mathrm{g} / \mathrm{m}^{2}\right)$, posterior wall thickness $(\mathrm{cm})$, septal thickness $(\mathrm{cm})$

Fractional shortening, ejection fraction (\%), relative wall thickness (wall stress), LV dysfunction (grades: none, mild, mild to moderate, moderate, moderate to severe, severe)

LA diameter $(\mathrm{cm})$, volume $(\mathrm{mL})$, volume index $\left(\mathrm{mL} / \mathrm{m}^{2}\right)$, and systolic area $\left(\mathrm{cm}^{2}\right)$

Qualitative RV dilatation (none, mild, moderate, severe) and base to apex length (cm), TV tethering distance (cm) and area $\left(\mathrm{cm}^{2}\right)$

Qualitative RV dysfunction (none, mild, moderate, severe), systolic pressure ( $\mathrm{mm} \mathrm{Hg}$ ), TAPSE (cm) and MPI, TV diameter shortening $(\mathrm{cm})$ and fractional shortening

Qualitative RA dilatation (none, mild, moderate severe) at end systole $\left(\mathrm{cm}^{2}\right)$ valve; TAPSE, tricuspid annular plane systolic excursion; $M P I$, myocardial performance index; $R A$, right atrial. 


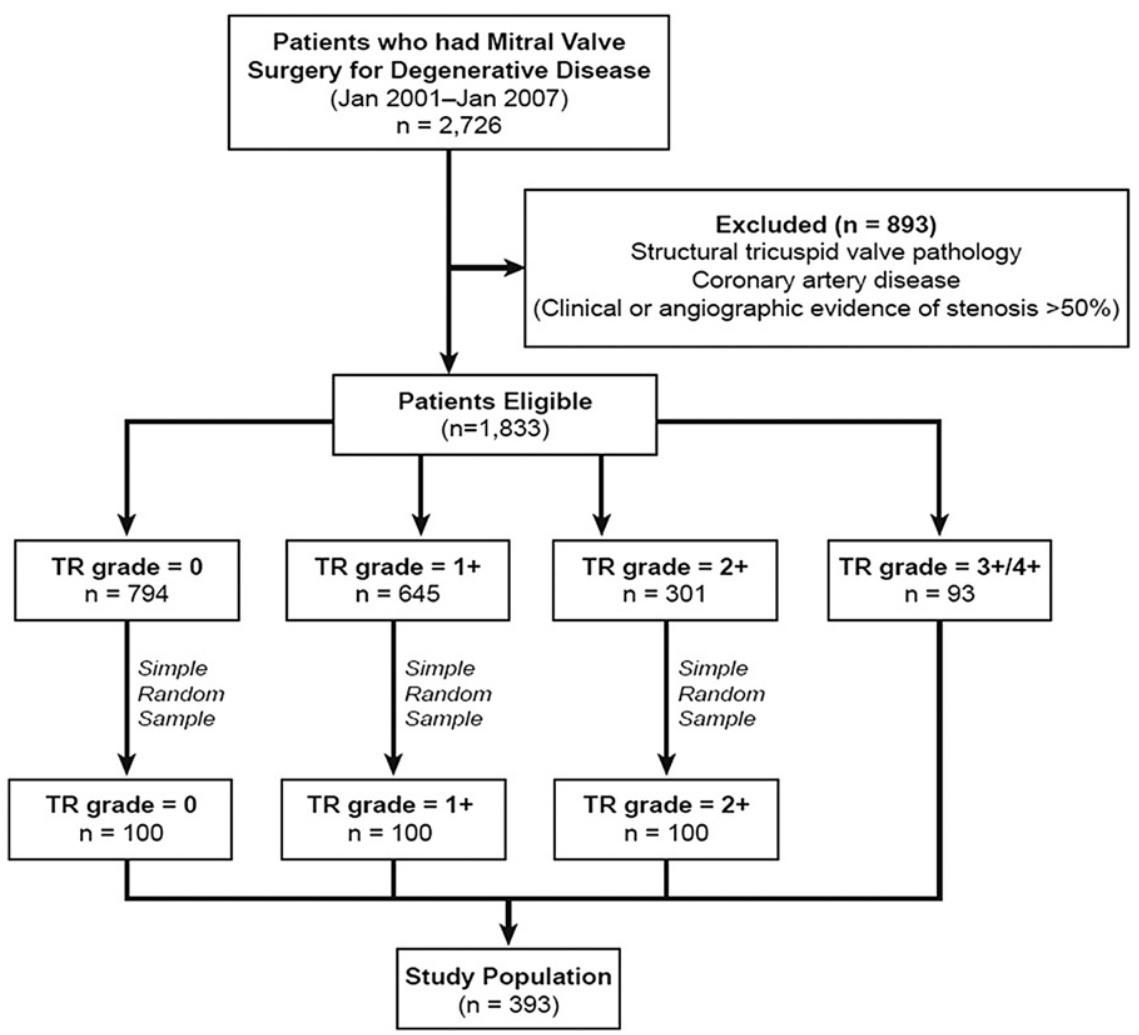

FIGURE E1. Consolidated Standards of Reporting Trials-type diagram showing study design and patient population. TR, Tricuspid regurgitation.
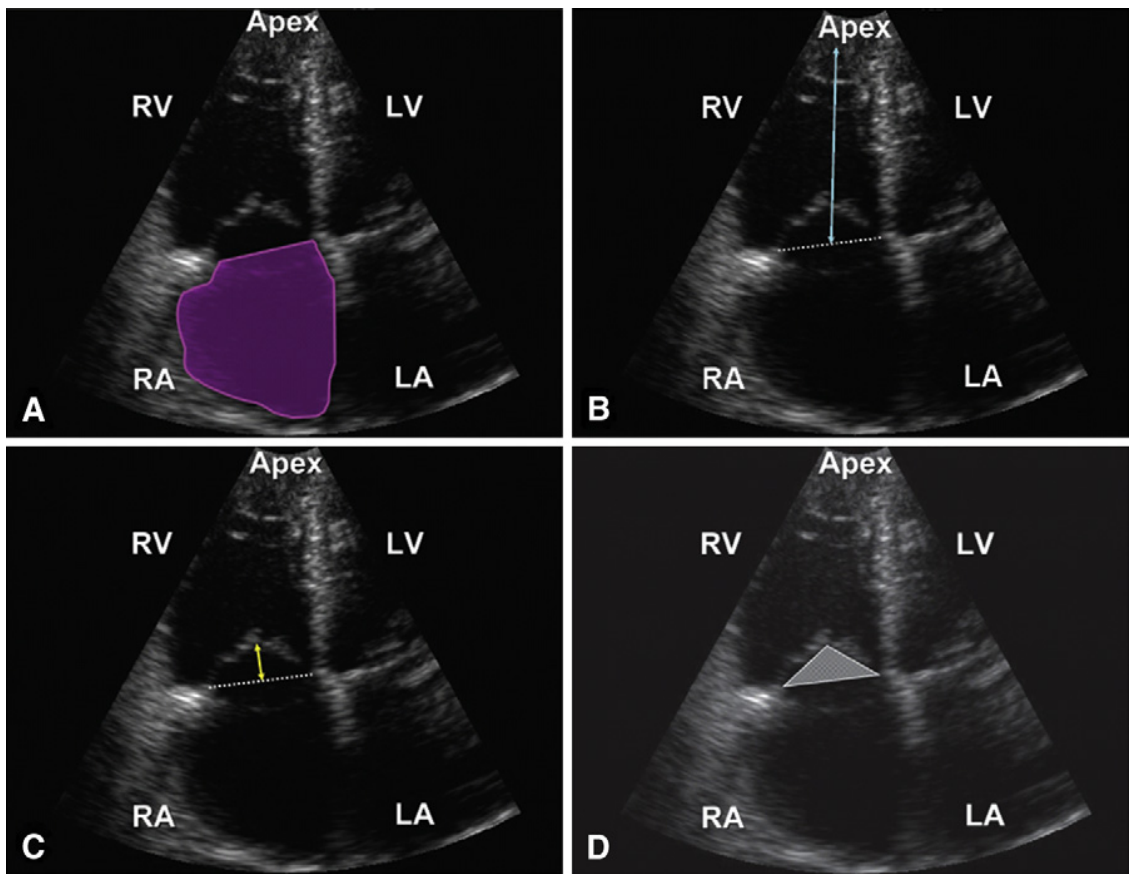

FIGURE E2. Transthoracic echocardiographic assessment of right-sided heart morphology using the apical 4-chamber view. A, RA systolic area shaded. $\mathrm{B}, \mathrm{RV}$ base-to-apex length. C, TV tethering distance in systole. D, TV tethering area in systole (shaded). $R V$, Right ventricle; $L V$, left ventricle; $R A$, right atrium; $L A$, left atrium. 


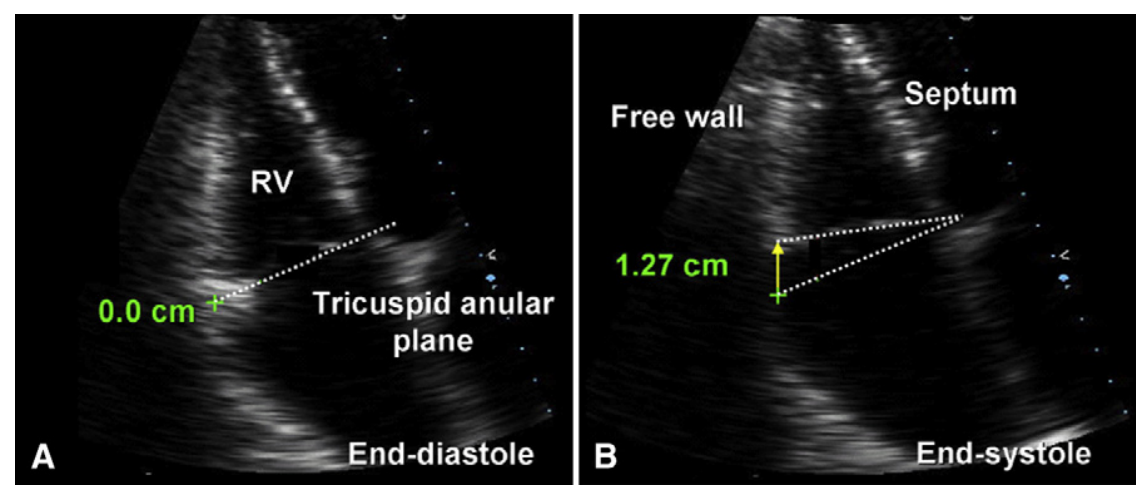

FIGURE E3. Transthoracic echocardiographic assessment of RV function: TAPSE. A, Annulus plane at end diastole (dotted line). B, TAPSE is measured at end systole. Arrow shows movement of tricuspid annular plane from end diastole to end systole. $R V$, Right ventricular.

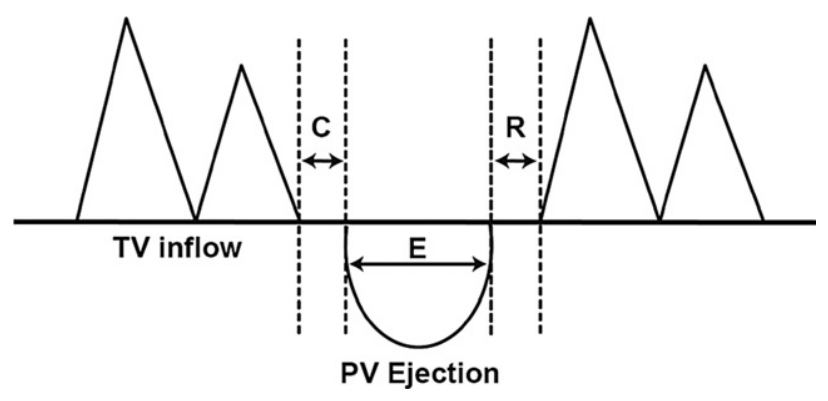

FIGURE E4. Transthoracic echocardiographic assessment of RV function: MPI. Schematic representation of Doppler intervals for calculating MPI. MPI $=(C+R) / E$, calculated by measuring the interval between cessation and onset of flow across TV and pulmonary valve ejection time. $C$, Isovolumetric contraction time; $R$, isovolumetric relaxation time; $E$, pulmonary ejection time; $T V$, tricuspid valve; $P V$, pulmonary valve.

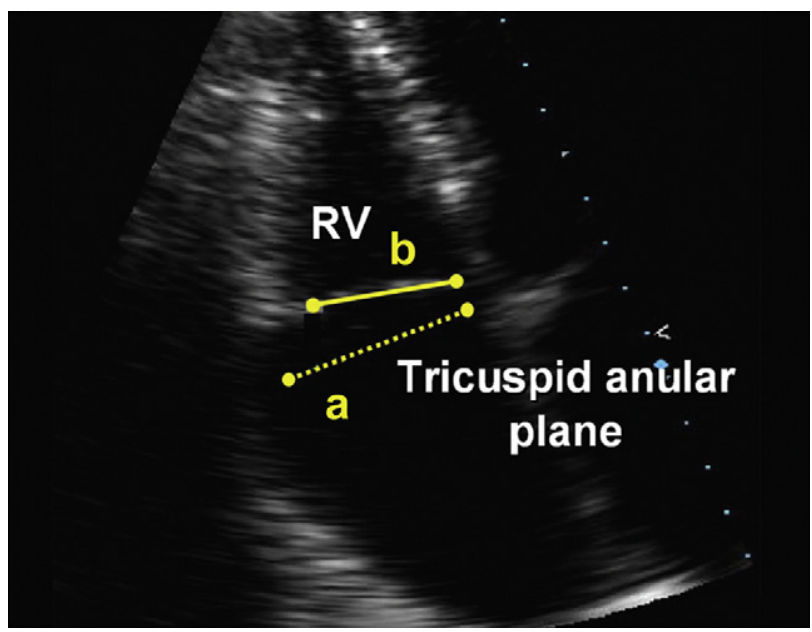

FIGURE E5. TV annular shortening. TV plane in diastole is shown as $a$ and in systole as $b . R V$, Right ventricle. 


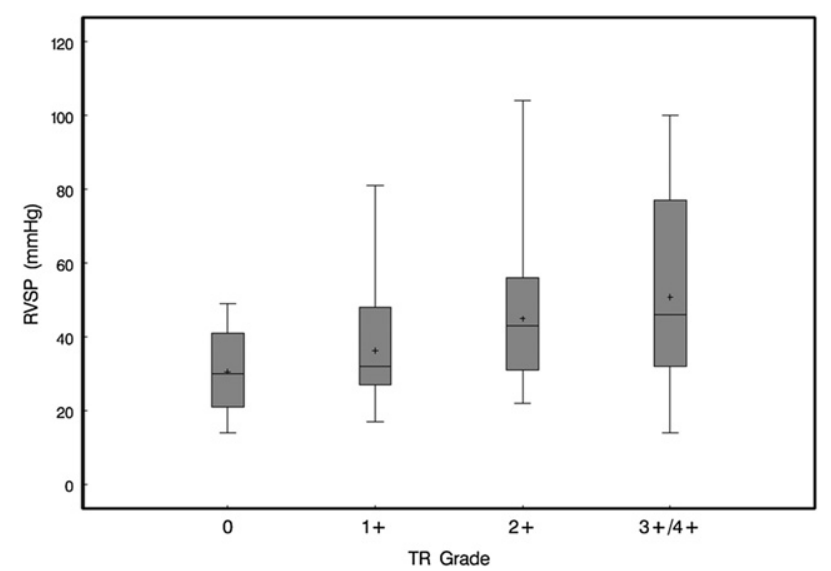

FIGURE E6. Box and whiskers plot of RVSP and TR grade. Whiskers represent extreme values, boxes represent the 15th and 85th percentile of values, + sign represents the mean, and horizontal bar represents the median values. RVSP, Right ventricular systolic pressure; $T R$, tricuspid regurgitation.
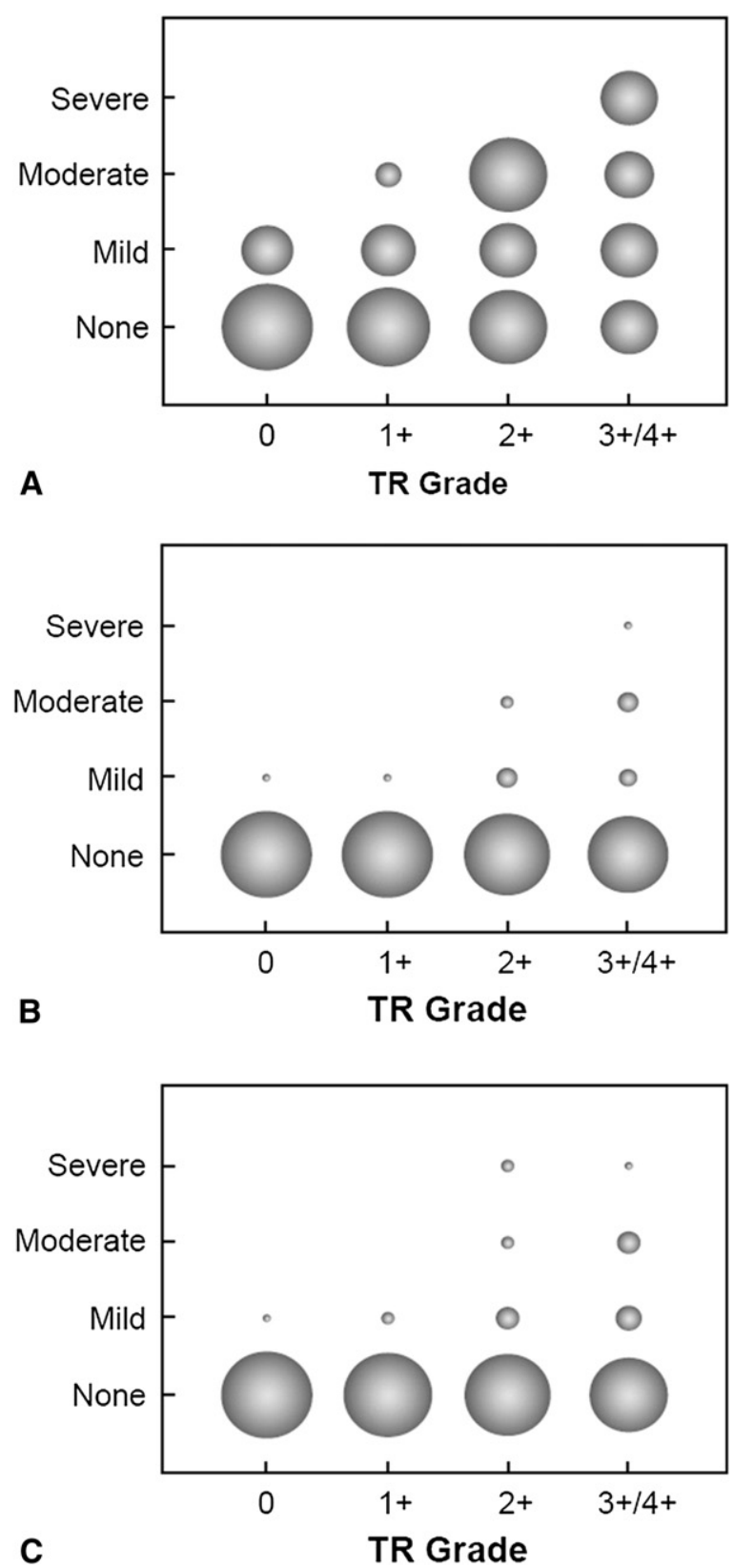

FIGURE E7. Bubble plots of qualitative clinical assessment of right-sided heart morphology and function associated with TR grade. Area of bubble corresponds to number of observations. A, RA dilatation grade. B, RV dilatation grade. C, RV dysfunction grade. $T R$, Tricuspid regurgitation. 

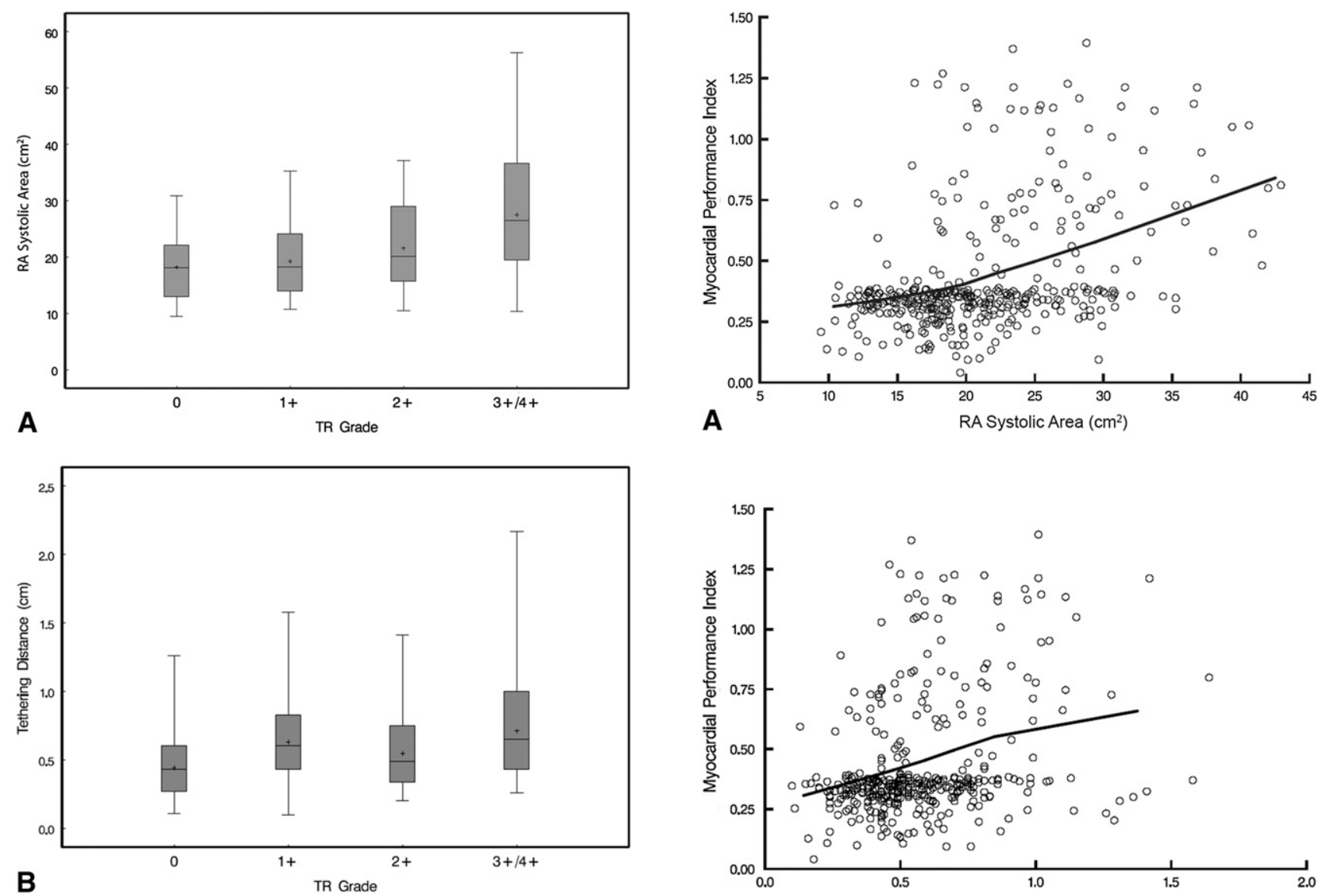

FIGURE E8. Box and whiskers plots of right-sided heart morphology and TR grade. Format is as in Figure E6. A, RA systolic area. B, TV tethering distance. $R A$, Right atrial; $T R$, tricuspid regurgitation.

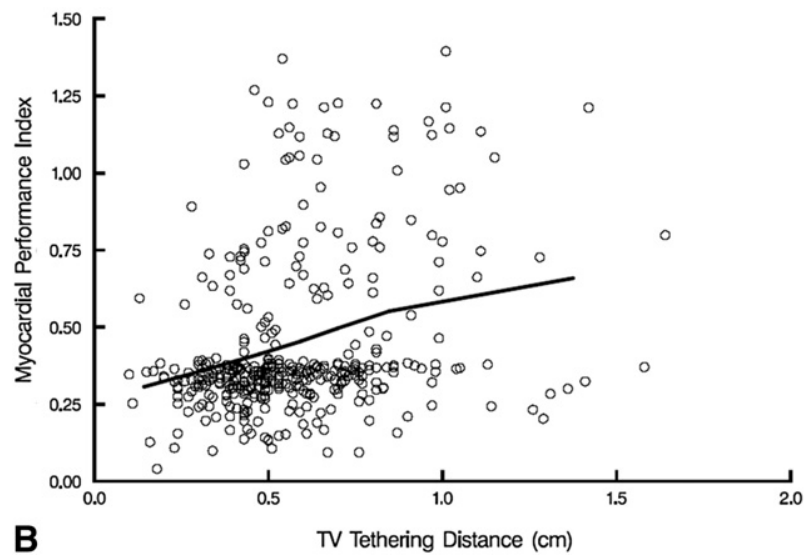

FIGURE E9. MPI and right-sided heart morphology. A, Scattergram of MPI and RA systolic area. Loess smoother shown as solid lines. B, Scattergram of MPI and TV tethering distance. $R A$, Right atrial; $T V$, tricuspid valve. 


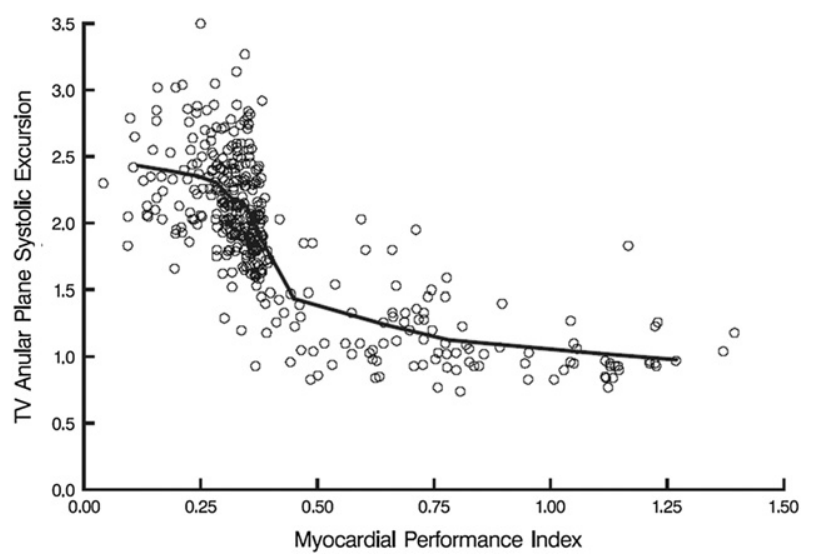

FIGURE E10. Scattergram of TAPSE and MPI. Loess smoother shown as solid lines. TV, Tricuspid valve.

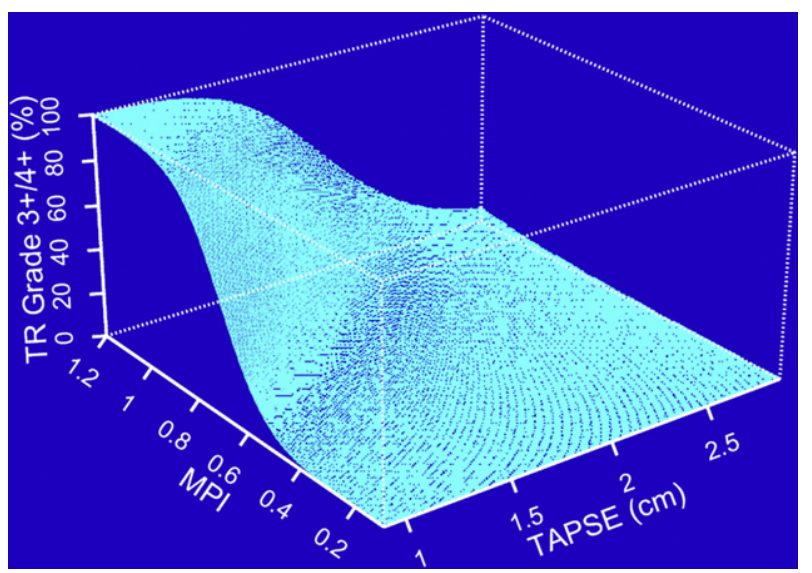

FIGURE E11. Three-dimensional perspective graph of TR grade, MPI, and TAPSE. TR, Tricuspid regurgitation; $M P I$, myocardial performance index; TAPSE, tricuspid annular plane systolic excursion.
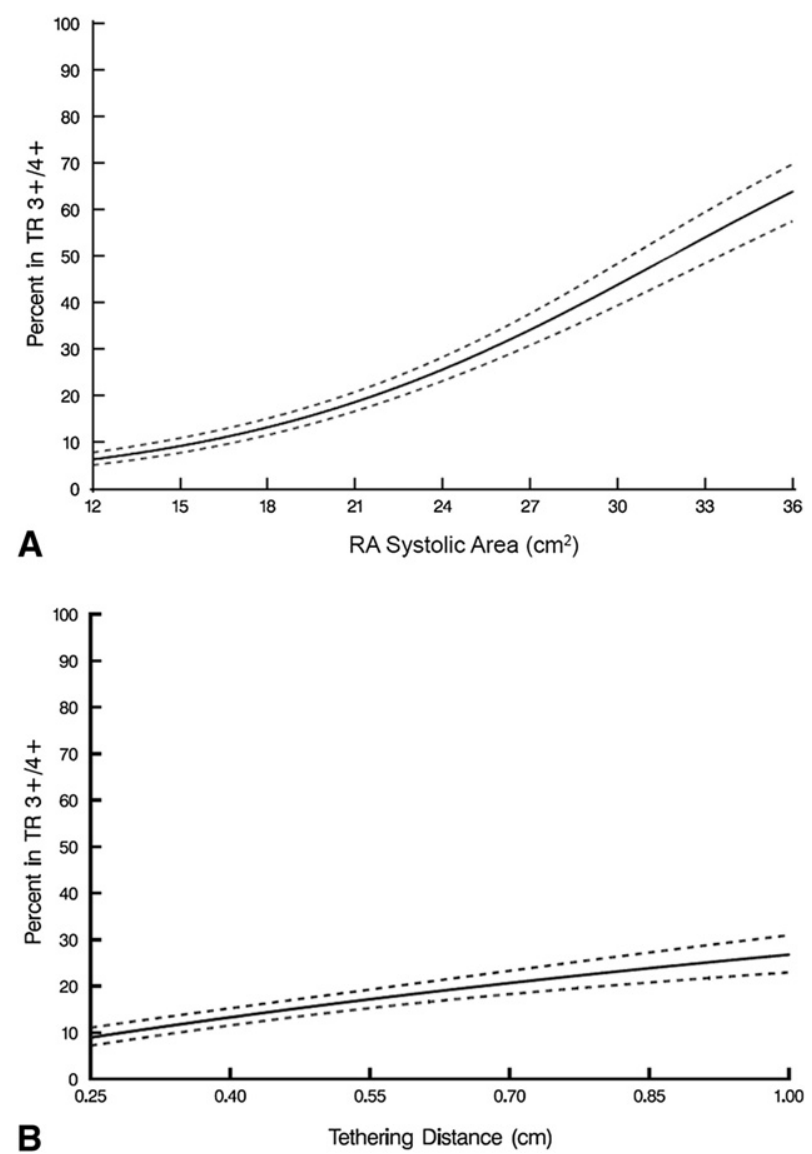

FIGURE E12. Nomogram based on multivariable equation (analysis 2 in Table 4) relating percentage of patients in TR grades $3+4+4$ to right-sided heart morphology. A, RA systolic area. B, Tethering distance. TR, Tricuspid regurgitation; $R A$, right atrial. 